\title{
Application of DNA markers in parentage verification of Boran cattle in
} Kenya

\author{
David Kios $^{1}{ }^{2}$, Estè Van Marle-Köster ${ }^{1}$ and Carina Visser ${ }^{1}$
}

${ }^{1}$ University of Pretoria, Department of Animal and Wildlife Sciences, P.O. Box Pretoria, 0002, Republic of South Africa

Moi University ${ }^{2}$, Chepkoilel University College, Department of Animal Science, P.O. Box 1125 (30100), Eldoret, Kenya

Corresponding author: Dr Este Van Marle-Köster, Department of Animal and Wildlife Sciences, University of Pretoria, Pretoria 0002, Republic of South Africa, Telephone +27 12420 3612, Fax +27 12420 3290, email Evm.koster@up.ac.za 


\section{Abstract}

Boran cattle provide livelihood to thousands of households in the arid and semi arid lands (ASAL) of Kenya. Due to their superior adaptive and productive traits in comparison to other breeds of cattle, they have also become a popular choice for breeders in Eastern and Southern Africa. Continued genetic improvement of the breed is important and therefore accurate performance and pedigree records are required. 178 Pedigree records and blood samples of four Boran stud herds were evaluated for accuracy of parentage allocation using 11 microsatellite markers recommended by ISAG for parentage verification. The panel of the 11 microsatellite markers were found to be highly polymorphic (PIC of 0.6901) with a combined probability of exclusion (CPE) of 0.9997 . The dam misidentification was low ranging between 0 and $5 \%$ for the herds tested. The estimated rate of mispaternity however ranged between 4.3 and $80 \%$ among the four stud herds and more than $50 \%$ of the offspring of some herds were misidentified. The high rate of mispaternity will have a negative impact on the response to selection. The use of DNA markers for parentage assignment will improve the accuracy of the pedigree records of Boran stud cattle in Kenya and contribute to more accurate selection of superior animals.

Keywords: Boran cattle, microsatellite markers, pedigree records, sire misidentification, genetic improvement

\section{Introduction}

The livestock sector in Kenya contributes $10-12 \%$ to the gross domestic product (GDP) (Mwangi \& Omore, 2004; Kabubo-Mariara, 2009), of which the Boran breed contributes approximately $2 \%$. Improving the productivity of the livestock production systems is crucial for poverty alleviation (Rege \& Gibson, 2003; Scarpa et al., 2003; Rewe et al., 2010) and the harsh conditions of the ASAL dictates the need for the use and improvement of the local cattle breeds 
such as the Boran. The Boran is a suitable breed for grass-fed beef production as they are well adapted to the Kenyan habitat and show a lower susceptibility to ticks and diseases (Hansen, 2004; Zander \& Drucker, 2008). Boran bulls are used in crossbreeding systems and crossbred Boran-sired calves have been shown to outperform Bos taurus sired contemporaries with regard to birth and weaning weights (Lunstra \& Cundiff, 2003). Boran embryos have been exported to Zambia, Zimbabwe, Australia, America, Brazil and South Africa (Cherogony \& Kios, 2008; Kios, 2008; KBCBS, 2010), confirming the importance and the growing popularity of the breed.

Boran cattle are kept on large commercial ranches where a lack of internal paddocks and fencing limit sound breeding and management practices. Especially the stud breeders experience problems in keeping their mating groups apart and depend on the herders to accurately record both mating and calving activities. Due to large farming units, breeders often make use of multiple sire mating strategies that further aggravates the problem of accurate sire identification. Although pedigree records are kept for stud Boran cattle by the breeders, most Boran cattle herds in Kenya have developed without the use of herd books (Zander et al., 2008) or an official scheme (Kahi et al., 2006). The unavailability of information from relatives in many Boran cattle populations has hindered the development of optimum breeding strategies.

Inaccurate pedigree information is a common problem in the livestock industry and paternity pedigree errors have a substantial negative impact on national genetic evaluation and estimates of inbreeding (Ron et al., 1996; Banos et al., 2001 Pollak, 2005; Dodds et al., 2007). The proportion of misidentified progeny varies between 2.9 and $23 \%$ in cattle worldwide (Geldermann et al., 1986; Weller et al., 2004; Van Eenennaam et al., 2007). Parentage verification is crucial as it forms the basis for accurate selection and improved rate of genetic progress (Dodds et al., 2005; Visscher et al., 2002) and becomes more critical with the wide spread use of artificial insemination, embryo transfer and multiple sire breeding schemes (Senneke et al., 2004; Sherman 
et al., 2004; Van Eenennaam et al., 2007). Beef producers should be able to determine the sires of all progeny in order to estimate their relative performance (Van Eenennaam et al, 2007), and this is possible with the aid of DNA based markers (Van Marle-Köster \& Nel, 2003; Gomez-Raya et al., 2008).

The accuracy of pedigree records of Boran cattle has not previously been determined and the level of parentage misidentification is unknown. The objective of the study was to quantify parentage recording errors and evaluate DNA-based parentage verification as a possible solution in Kenyan Boran stud herds.

\section{Materials and Methods}

\section{Materials}

Four Boran stud herds that are members of the Kenya Boran Cattle Breeders Society (KBCBS) and Kenya Stud Book (KSB) provided samples and pedigree records for this study. Three of the herds were kept in large ranches of over 50,000 acres of land with at least 4,000 head of cattle each with limited fencing and herd management. The breeding cow herds are reared in groups of $150-200$ heads which are exposed to a bull for ten weeks and allowed to rest for two weeks before introducing the next bull. No specific mating season was followed and mating took place throughout the year. The fourth herd was kept on a smaller farm of 300 head of cattle with both external and internal paddocks. Mating and calving was closely monitored due to the effective separation of the livestock.

The cattle were handled in their normal environment in accordance with the protocols. Samples of $5 \mathrm{ml}$ blood was collected from each of the 178 head of cattle from the four sire families (Table 1) in vacutainer tubes containing EDTA and kept at $-20^{\circ} \mathrm{C}$ for further analysis. Permission to use Boran cattle DNA was obtained from the Ethics committee on Biohazards in the Faculty of 
Natural and Agricultural Sciences of the University of Pretoria (Ref. No: EC091005-54), the Director of Animal Health of the Republic of South Africa, the Director of Veterinary services in Kenya and the KBCBS.

Table 1 The distribution of samples and herd size / ranch size of the four stud herds

\begin{tabular}{lccllll}
\hline Stud & No Sampled & Herd size & Dams & Progeny & Sire & $\begin{array}{l}\text { Ranch size } \\
\text { (acres) }\end{array}$ \\
\hline I & 48 & $>4000$ & 23 & 24 & 1 & $>50,000$ \\
II & 41 & $>4000$ & 20 & 20 & 1 & $>50,000$ \\
III & 41 & $>4000$ & 20 & 20 & 1 & $>50,000$ \\
IV & 48 & 300 & 23 & 24 & 1 & $<10,000$ \\
\hline
\end{tabular}

\section{Methods}

DNA extraction was performed using GFX Genomic Blood DNA Purification kits from Amersham Biosciences (www.amersham.com) and the DNeasy Blood and Tissue kit for DNA purification from Qiagen (www.qiagen.com) according to the manufacturers' protocol. DNA quantification was performed using agarose gel electrophoresis (Amersham Pharmacia Biotech Inc) and nanodrop spectrophotometer (NanoDrop Technologies, Inc., http://www.nanodrop.com). The 178 DNA samples had concentrations of $50-100 \mathrm{ng} / \mu 1$, adequate for the research.

Nine of the 12 microsatellite markers (BM1824, BM2113, SPS115, TGLA122, TGLA126, TGLA227, INRA023, ETH10 and ETH225) used in this study were selected based on the recommendation of the International Society for Animal Genetics (ISAG) (www.isag.org.uk) for routine use in cattle parentage verification. Three additional microsatellite markers, TGLA53, BM1818 and SPS113 were selected based on their high heterozygosity and polymorphic information content, their ease of amplification and fragment size relative to the other nine, as reported in the literature. SPS 113 was excluded from this study due to repeated failure to amplify. 
DNA amplification was done using the polymerase chain reaction (GeneAMP® PCR system 9700 thermocycler, Applied Biosystems, Foster City, USA) with the following PCR program: An initial denaturation for 5 minutes at $94^{\circ} \mathrm{C}$, followed by 30 cycles of; denaturation at $94^{\circ} \mathrm{C}$ for 30 seconds, annealing temperature for 1 minute and extension at $72^{\circ} \mathrm{C}$ for 1 minute, and a final extension at $72^{\circ} \mathrm{C}$ for 7 minutes. The reaction solution for PCR was: $2.0 \mu 1$ PCR buffer $(5 \mathrm{x}$ GoTaq buffer), $0.8-1.0 \mu \mathrm{MgCl}(25 \mathrm{mM}), \quad 0.5 \mu 1 \mathrm{dNTPs}(10 \mathrm{nM}), 0.4 \mu 1$ forward primer (10pmol $/ \mu \mathrm{l}), 0.4 \mu \mathrm{l}$ reverse primer $(10 \mathrm{pmol} / \mu \mathrm{l}), 0.5 \mu \mathrm{l}$ GoTaq polymerase $(5 \mathrm{U} / \mu \mathrm{l})$ and $4 \mu \mathrm{l}$ DNA $(50-100 \mathrm{ng} / \mu \mathrm{l})$. Deionised water was added to obtain a final solution of $15 \mu \mathrm{l}$.

Genotyping was performed with ABIPRISM ${ }^{\circledR} 3100$ Genetic Analyzer (Applied Biosystems, Foster City, USA) for DNA sequencing and fragment analysis. The electropherogram was analysed using Genemarker software version 1.8 (Softgenetics) (http://www.softgenetics.com) and the genotypes were verified for consistency, peak sizes and fragment size. Allelic frequencies were estimated for the genotype dataset using Microsatellite toolkit (Park, 2001) and Cervus version 3.0 (Marshall et al., 1998) software. Parentage assignment and exclusion statistics were performed using Cervus 3.0 based on likelihood equations that accommodate genotyping errors and increase the number of paternities that can be assigned at $80 \%$ (relaxed) and $95 \%$ (strict) confidence level (Marshall et al., 1998; Kalinowski et al., 2007).

\section{Results}

The results of the individual microsatellite marker evaluation are shown in Table 2 . The markers were highly informative and complied with the prerequisites for parentage verification which requires expected heterozygosity $\left(\mathrm{H}_{\text {exp }}\right)$ and polymorphic information content (PIC) values of above 0.5 (Marshall et al., 1998). The combined probability of exclusion for the first (CPE-1) and second parent (CPE-2) of the 11 microsatellite markers panel were 0.990 and 0.9997 respectively. The average amplification success over all samples was $95.3 \%$, with six markers showing a 
success rate in excess of $97 \%$. Three samples failed to amplify repeatedly and were excluded from the study. The microsatellite markers were non significant for Hardy - Weinberg equilibrium test, and are assumed to be in linkage equilibrium. Very low null-allele frequencies were reported for all markers, with no marker approaching the 0.05 limit proposed by Marshall et al. (1998) for exclusion from a parentage verification panel.

Table 2 Parameters of microsatellite markers used for parentage verification

\begin{tabular}{lllllllllll}
\hline Locus & $\mathbf{k}$ & $\mathbf{n}$ & $\mathbf{\%}$ Suc & Hobs & Hexp & PIC & PE-1 & PE-2 & Null & HW \\
\hline TGLA122 & 9 & 174 & 97.6 & 0.77 & 0.758 & 0.727 & 0.376 & 0.557 & -0.0061 & NS \\
ETH10 & 7 & 174 & 97.6 & 0.69 & 0.635 & 0.609 & 0.247 & 0.435 & -0.0561 & NS \\
BM1818 & 7 & 174 & 97.6 & 0.707 & 0.723 & 0.688 & 0.328 & 0.511 & 0.0057 & NS \\
TGLA126 & 7 & 173 & 97.2 & 0.815 & 0.793 & 0.761 & 0.414 & 0.593 & -0.0196 & NS \\
ETH225 & 7 & 173 & 97.2 & 0.613 & 0.618 & 0.593 & 0.233 & 0.42 & 0.003 & NS \\
TGLA53 & 13 & 173 & 97.2 & 0.867 & 0.824 & 0.8 & 0.481 & 0.655 & -0.0261 & NS \\
BM1824 & 6 & 172 & 96.6 & 0.703 & 0.73 & 0.681 & 0.311 & 0.485 & 0.0224 & NS \\
TGLA227 & 10 & 172 & 96.6 & 0.651 & 0.664 & 0.613 & 0.253 & 0.421 & 0.0136 & NS \\
BM2113 & 10 & 171 & 96.1 & 0.83 & 0.812 & 0.782 & 0.445 & 0.622 & -0.0134 & NS \\
INRA023 & 10 & 165 & 92.7 & 0.727 & 0.754 & 0.715 & 0.361 & 0.538 & 0.0157 & NS \\
SPS115 & 7 & 161 & 90.4 & 0.671 & 0.658 & 0.623 & 0.258 & 0.44 & 0.0229 & NS \\
CPE & & & & & & & $\mathbf{0 . 9 9 0 1}$ & $\mathbf{0 . 9 9 9 7}$ & & \\
MEAN & $\mathbf{8 . 4 5}$ & & $\mathbf{9 5 . 3}$ & & $\mathbf{0 . 7 2 4 6}$ & $\mathbf{0 . 6 9 0 1}$ & & & & \\
\hline
\end{tabular}

K: Number of alleles, n: Number of samples, \% Suc: comparative amplification success as percentage, Hobs: Observed heterozygosity, Hexp: Expected heterozygosity, PIC: Polymorphic information content, PE-1: Probability of exclusion first parent, PE-2: Probability of exclusion second parent, CPE: Combined probability exclusion (first and second parent), Null: Null allele frequency, HW: Hardy - Weinberg equilibrium

The results of parentage verification analyses of the four sire families are presented in Table 3. Of the 87 offspring analysed, the genotypes of 85 matched with that of their dams and only two mismatches were reported. There were four loci mismatches between the dam and her offspring in stud herd I with a resulting -1.33 LOD score. The dam and her offspring in stud herd III had three loci mismatches with a -1.25 LOD score. All maternity records of stud herds II and IV were 
confirmed by the molecular analyses, with no mismatches. One offspring each in stud herds I and III mismatched with their reported dams. This was in sharp contrast with the paternity records. The genotypes of only 39 offspring matched with that of their recorded sires, while 48 offspring were misallocated. The sire misallocation percentage varied greatly between herds $(4.3 \%$ in herd IV vs. $80 \%$ in herd III). The average dam misidentification across all herds was $2.3 \%$, while the sire misidentification was very high $(55.2 \%)$ over the four stud herds.

Table 3 Parentage verification results of the four Boran stud herds showing number of animals compared, number of matched and mismatched offspring and parents, mismatched loci and percentage mismatches

\begin{tabular}{lllllllllll}
\hline Stud & N & Offsp & MD & MM & ML & \%MM & MP & Mispat & PL & \%MP \\
\hline Herd I & 47 & 24 & 23 & 1 & 4 & 4.2 & 7 & 17 & $1-6$ & 71 \\
Herd II & 41 & 20 & 20 & 0 & 0 & 0 & 6 & 14 & $2-6$ & 70 \\
Herd III & 41 & 20 & 19 & 1 & 3 & 5 & 4 & 16 & $1-6$ & 80 \\
Herd IV & 46 & 23 & 23 & 0 & 0 & 0 & 22 & 1 & 3 & 4.3 \\
Total & $\mathbf{1 7 5}$ & $\mathbf{8 7}$ & $\mathbf{8 5}$ & $\mathbf{2}$ & & $\mathbf{2 . 3}$ & $\mathbf{3 9}$ & $\mathbf{4 8}$ & & $\mathbf{5 5 . 2}$ \\
\hline
\end{tabular}

N: number of animals (sire, dam, offspring), Offsp: offspring, MD: number of matched offspring and dams, MM: number of mismatched offspring and dams, ML: number of loci mismatch between dam and offspring, \% MM: \% offspring and dam mismatch, MP: number of matched offspring and sires, Mispat: number of mismatched offspring and sires, PL: range of loci mismatch between sires and offspring and \% MP: \% offspring and sire mismatch

\section{Discussion}

In this study DNA based parentage verification was used to evaluate parentage recording in Kenyan Boran cattle. The microsatellite markers selected were first analysed for individual parameters influencing their suitability for inclusion in a parentage verification panel. The 11 microsatellite markers were polymorphic with an average number of alleles of 8.45 per locus. It should be noted that the animals tested were related and a higher number of alleles will be 
expected if larger samples of Boran cattle is to be tested. Other studies in beef cattle have reported mean number of alleles of 9 (Sherman et al., 2004; Van Eennenaam et al., 2007). The $\mathrm{H}_{\text {exp }}$ range (0.618 to 0.824$)$ and $\mathrm{H}_{\mathrm{obs}}(0.613$ to 0.867$)$ were in agreement to those reported by Sherman et al., (2004) in a similar study (0.588 to 0.843$)$. The mean polymorphic information content (PIC) was 0.6901 and corresponded to those determined previously, which ranged from 0.626 to 0.640 in beef cattle (Cervini et al., 2006; Van Eennenaam et al., 2007).

The $\mathrm{H}_{\text {exp }}$ and PIC values of above 0.5 and null frequency values of below 0.05 were adequate for inclusion in a parentage verification panel (Marshall et al., 1998). When combined into a panel, the microsatellite markers had a high exclusion power with a combined probability of exclusion for first parent (CPE-1) of 0.9901 and second parent (CPE-2) of 0.9997. Studies performed in beef cattle using similar markers have reported CPE-1 values of $0.9684-0.9936$ and CPE-2 values of 0.9989 to 0.9999 (Sherman et al., 2004; Cervini et al., 2006; Van Eenennaam et al., 2007). The CPE values were sufficient to exclude non parents in the parentage analysis of the four Boran stud herds.

Two of the four herds managed $100 \%$ correct recording of dams to offspring, while the other two herds had one recording error each. The two instances of incorrect dam records could have been caused by switching of the calves at birth, incorrectly identifying the dams and offspring during blood sampling or incorrect recording of the pedigree information in the herd book (Weller et al., 2004). The low level of dam misidentification in this study indicates this as a minor problem.

The rate of sire misidentification in the four herds ranged between 4.3 and $80 \%$. Previously reported rates of misidentification or missing sires in beef cattle include $12 \%$ reported by Van Eenennaam et al. (2007), 14\% reported by Sherman et al. (2004) and 0-33.6\% reported by Holroyd et al. (2002). The high rate of sire misidentification in this study is cause for concern as 
paternal identification is critical for improvement of the rate of genetic progress (Pollak, 2005) and effective monitoring of inbreeding (Cassell et al., 2003).

The mating strategy of all year joining practiced by the Boran cattle breeders makes it difficult to accurately record most of the mating events. The sires in Kenyan ranches are used for 10 weeks, then rested and a new bull introduced after a two week rest of the breeding cows. This was meant to aid in identification of the sire of the offspring but the two week rest period is too short to adequately identify the offspring of the sires if a supposedly pregnant cow is served by the new bull in the field. The lack of internal and external paddocks to separate breeding herds during the mating period may also lead to other sires straying from commercial herds and the neighboring farms to the stud herds. Similar observations have been reported on other beef ranches (Van Eenennaam et al., 2007).

The extensive system of beef production in most ranches may lead to ineffective monitoring of mating events (Gomez-Raya et al., 2008; Yagüe et al., 2009) and limit the use of the reproductive information for selection. Recording of successful mating in the field may not be effective as most of the herders in Kenyan ranches have no formal education and these records are prone to human error. Late identification and registration of the offspring may also contribute to sire misidentification. The offspring in the three ranches with high sire misidentification rate were branded at weaning and sire records may have been incorrectly entered into the herd book. Similar observation was reported for sheep with late pedigree recording (Bolormaa et al., 2008).

Some of these causes can be controlled by improved recording but the extensive system of production under harsh climatic conditions and infrastructural challenges are limiting factors and DNA based parentage assignment may be the solution. The breeder of stud herd IV had the most accurate pedigree records for both dams and sires. Cattle recording require accurate identification 
of the sire, dam, and the progeny with proper maintenance of the records, a difficult task in the multiple sire breeding systems in use. Stud herd IV is kept in a relatively smaller fully paddocked farm and the recording and identification of calves is done immediately after birth. These could be the reasons for the low sire misidentification rate in this herd.

The overall sire misidentification rate in this study was $55.2 \%$ and with such a high rate, genetic progress of the breed will be slow and may even be negative (Banos et al., 2001). It renders the use of pedigree records inappropriate to monitor genetic progress and inbreeding trends (Wiggans et al., 1995). The stud herds rely on performance and progeny testing for continued improvement of the breed. Superior sires with misidentified progeny may be culled due to poor performance of the purported progeny leading to loss of superior genetics (Gomez-Raya et al., 2008). Incorrect identification of sires can bias estimates of heritability, breeding values and genetic progress (Israel \& Weller, 2000). The use of DNA-based parentage verification can mitigate several of the management challenges in Kenya and result in more accurate selection and a faster rate of genetic progress.

\section{Conclusion}

This study has shown that DNA technology can positively contribute to increased accuracy of pedigree information. The high rate of sire misidentification, the extensive production system practiced by Boran cattle breeders and infrastructural challenges render the genetic improvement of this breed difficult without the use of molecular techniques. This was the first attempt to verify pedigree accuracy in Kenyan ranches using DNA based parentage verification.

\section{Acknowledgement}

We thank Moi University's School of Agriculture \& Biotechnology and MU - VLIR UOS for the scholarship grants and the Kenya Boran Cattle Breeders Society for the use of Boran cattle. 


\section{References}

Banos, G, Wiggans, G.R, Powell, R.L, 2001. Impact of paternity errors in cow identification on genetic evaluations and international comparisons. Journal of Dairy Science 84: 2523 2529.

Bolormaa, S, Ruvinsky, A, Walkden-Brown, S, Van der Werf, J, 2008. DNA based parentage verification in two Australian goat herds. Small Ruminant Research 80: 95-100.

Cassell, B.G, Adamec, V, Pearson, R.E, 2003. Effect of Incomplete Pedigrees on Estimates of Inbreeding and Inbreeding Depression for Days to First Service and Summit Milk Yield in Holsteins and Jerseys. Journal of Dairy Science 86: 2967 - 2976.

Cervini, M, Henrique-Silva, F, Mortari, N, Matheucci, E. Jr, 2006. Genetic variability of 10 Micrsatellite Markers in characterization of Brazilian Nellore cattle (Bos Indicus), Genetics and Molecular Biology: 29, 3, 486-490.

Cherogony, M.R, Kios, D.K, 2008. Embryo Transfer: the ADC experience. In: Joint ILRI / EMBRAPA workshop at Kapiti plains, Kenya.

Dodds, K.G, Tate, M.L, Sise, J.A, 2005. Genetic evaluation using parentage information from genetic markers. Journal of Animal Science 83: 2271-2279.

Dodds, K.G, McEwan, J.C, Davis, G.H, 2007. Integration of molecular and quantitative information in sheep and goat industry breeding programmes. Small Ruminant Research 70: $32-41$.

Geldermann, H, Pieper, U, Weber, W.E, 1986. Effect of misidentification on the estimation of breeding value and heritability in cattle. Journal of Animal Science 63: 1759-1768.

Gomez-Raya, L, Priest, K, Rauw, W.M, Okomo-Adhiambo, M., Thain, D, Bruce, B, Rink, A, Torell, R, Grellman, L, Narayanan, R, Beattie, C.W, 2008. The value of DNA paternity 
identification in beef cattle: Examples from Nevada's free-range ranches. Journal of Animal Science 86:17-24.

Hansen, P.J, 2004. Physiology and Cellular adaptation of Zebu cattle to thermal stress. Animal Reproduction Science 82-84: 349-360.

Holroyd, R.G, Doogan, V.J, De Faveri, J, Fordyce, G, McGowan, M.R, Bertram, J.D, Vankan, D.M, Fitzpatrick, L.A, Jayawardhana, G.A, Miller, R.G, 2002. Bull selection and use in northern Australia 4. Calf output and predictors of fertility of bulls in multiple-sire herds. Animal Reproduction Science 71: 67-79.

Israel, C, Weller, J.I, 2000. Effect of misidentification on genetic gain and estimation of breeding value in Dairy cattle populations. Journal of Dairy Science 83: $181-187$.

Kabubo-Mariara, J, 2009. Global warming and livestock husbandry in Kenya: Impacts and adaptations. Ecological Economics 68: 1915 - 1924.

Kahi, A.K, Wasike, C.B, Rewe, T.O, 2006. Beef production in arid and semi-arid lands: Constraints and prospects for research and development. Outlook on Agriculture 35: 217 225.

Kalinowski, S.T, Taper, M.L, Marshall, T.C, 2007. Revising how the computer program CERVUS accommodates genotyping error increases success in paternity assignment. Molecular ecology 16: 1099 - 1106.

KBCBS, 2010. Boran cattle breeders' society of Kenya, http://www.borankenya.org/home.htm

Kios, D.K, 2008. Embryo transfer in Kenya. In: Scientific seminar and AGM Kenya Veterinary Association Rift Valley Branch., Kabarnet, Kenya.

Lunstra, D.D, Cundiff, L.V, 2003. Growth and pubertal development in Brahman-, Boran-, Tuli-, Belgian Blue-, Hereford- and Angus-sired F1 bulls. Journal of Animal Science 81:14141426. 
Marshall, T.C, Slate, J, Kruuk, L.E.B, Pemberton, J.C., 1998. Statistical confidence for likelihood-based paternity inference in natural populations. Molecular Ecology 7: 639655.

Mwangi, D.M, Omore, A, 2004. The livestock revolution - A view on implication for Africa. In: Responding to the livestock revolution, British Society of Animal Science 33: $51-66$.

Park, S.D.E, 2001. Trypanotolerance in West African cattle and the population genetic effects of selection. Ph.D Thesis, University of Dublin.

Pollak, E.J, 2005. Application and impact of new genetic technologies on beef cattle breeding: a "real world" perspective. Australian Journal of Experimental Agriculture 45, 739-748.

Rege, J.E.O, Gibson, J.P, 2003. Animal genetic resources and economic development: Issues in relation to economic valuation. Ecological Economics 45: 319 - 330 .

Rewe, T.O, Herold, P, Piepho, H-P, Kahi, A.K, Valle Zárate, A, 2010. Genetic and economic evaluation of a basic breeding programme for Kenya Boran cattle. Tropical Animal Health Production 42:327-340.

Ron, M, Blanc, Y, Band, M, Ezra, E, Weller, J.I, 1996. Misidentification Rate in the Israeli Dairy Cattle Population and Its Implications for Genetic Improvement. Journal of Dairy Science $79: 676-681$.

Scarpa, R, Ruto, E.S.K, Kristjanson, P, Radeny, M, Drucker, A.G, Rege, J.E.O, 2003. An empirical comparison of stated and revealed preference value estimates. In: Valuing indigenous cattle breeds in Kenya. Ecological Economics 45: 409 - 426.

Senneke, S.L, MacNeil, M.D, Van Vleck, L.D, 2004. Effects of sire misidentification on estimates of genetic parameters for birth and weaning weights in Hereford cattle. Journal of Animal Science 82: $2307-2312$.

Sherman, G.B, Kachman, S.D, Hungerford, L.L, Rupp, G.P, Fox, C.P, Brown, M.D, Feuz, B.M, T. R. Holm, T.R, 2004. Impact of candidate sire number and sire relatedness on DNA 
polymorphism-based measures of exclusion probability and probability of unambiguous parentage. Animal Genetics 35: 220-226.

Van Eenennaam, A.L, Weaber, R.L, Drake, D.J, Penedo, M.C.T, Quaas, R.L., Garrick, D.J, Pollak, E.J, 2007. DNA based paternity analysis and genetic evaluation in a large commercial cattle ranch setting. Journal of Animal Science 85:3159-3169.

Van Marle- Köster, E, Nel L.H., 2003. Genetic markers and their application in livestock breeding in South Africa: A review. South African Journal of Animal Science 33 (1).

Visscher, P.M, Woolliams, J.A, Smith, D, Williams, J.I, 2002. Estimation of pedigree error in the UK Dairy population using microsatellite markers and the impact on selection. Journal of Dairy Science 85: $2368-2375$.

Weller, J.I, Feldmesser, E, Golik, M, Tager- Cohen, I, Domochovsky, R, Alus, O, Ezra, E, Ron, M, 2004. Factors affecting incorrect paternity assignment in the Israeli Holstein population. Journal of Dairy Science 87: 2627 - 2640.

Wiggans, G.R, VanRaden, P.M, Zuurbier, J, 1995. Calculation and Use of Inbreeding Coefficients for Genetic Evaluation of United States Dairy Cattle. Journal of Dairy Science $78: 1584-1590$.

Yagüe, G, Goyache, F, Becerra, J, Moreno,C, Sanchez, L, Altarriba, J, 2009. Bayesian estimates of genetic parameters for preconception traits, gestation length and calving interval in beef cattle. Animal Reproductive Science 114: 72-80.

Zander, K.K, Drucker, A.G, 2008. Using Choice Model scenarios to value local cattle breeds in East Africa. In: Conserving what is important. Ecological Economics 68: 34-45.

Zander, K.K, Drucker, A.G, Holm-Muller, 2008. The case of the Borana cattle in Ethiopia and Kenya. In: Costing the conservation of Animal genetic resources. Journal of Arid Environments 1-7. 